\title{
Science and Technology Gaps in Underground Coal Gasification
}

Ravi Upadhye, Elizabeth Burton, Julio Friedmann

June 30, 2006 
This document was prepared as an account of work sponsored by an agency of the United States Government. Neither the United States Government nor the University of California nor any of their employees, makes any warranty, express or implied, or assumes any legal liability or responsibility for the accuracy, completeness, or usefulness of any information, apparatus, product, or process disclosed, or represents that its use would not infringe privately owned rights. Reference herein to any specific commercial product, process, or service by trade name, trademark, manufacturer, or otherwise, does not necessarily constitute or imply its endorsement, recommendation, or favoring by the United States Government or the University of California. The views and opinions of authors expressed herein do not necessarily state or reflect those of the United States Government or the University of California, and shall not be used for advertising or product endorsement purposes.

This work was performed under the auspices of the U.S. Department of Energy by University of California, Lawrence Livermore National Laboratory under Contract W-7405-Eng-48. 


\title{
Science and Technology Gaps in Underground Coal Gasification
}

\author{
Ravi Upadhye, Liz Burton, and Julio Friedmann \\ Lawrence Livermore National Laboratory \\ Science and Technology Gaps in Underground Coal Gasification............................... 1

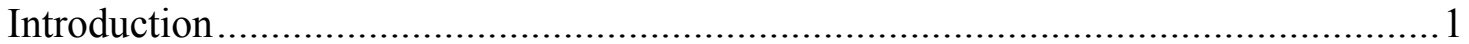

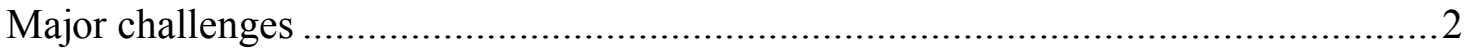 \\ Improved process control - volume and quality of gas .................................... 2

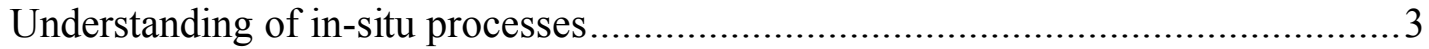

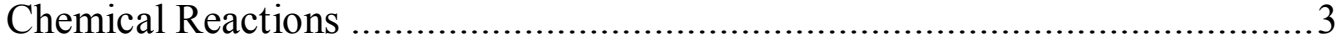 \\ Bulk and in-pore Mass Transfer ................................................................... 3

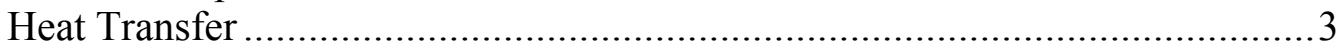

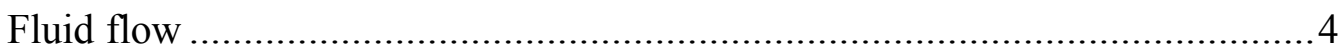

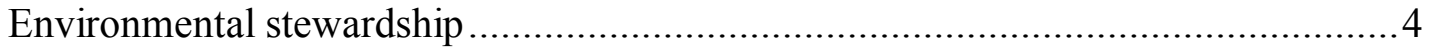

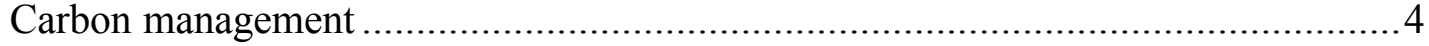 \\ Location of Carbon (CO2) Capture …............................................................ 5 \\ Separation Technologies ....................................................................... 5

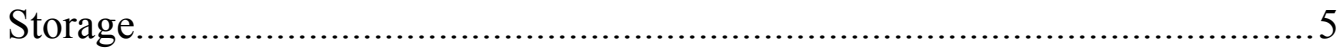

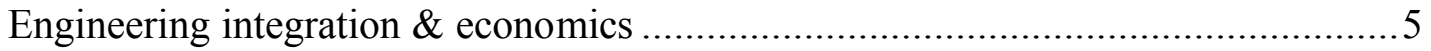

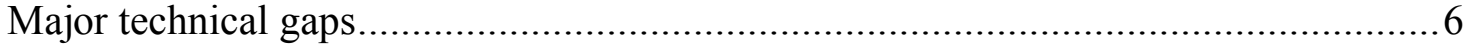 \\ Improved combustion/gasification models ...................................................... 6

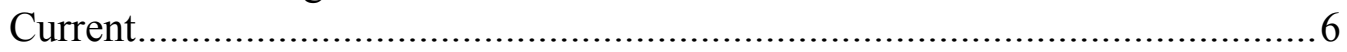

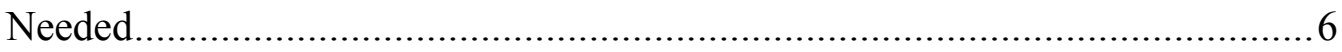

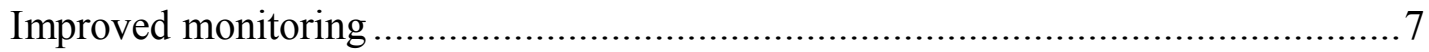

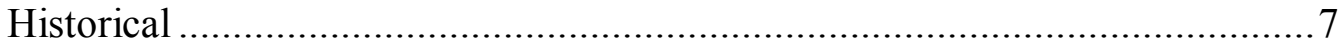

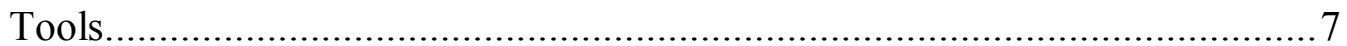 \\ Likely learnings from field deployment................................................ 8

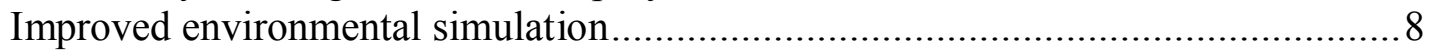

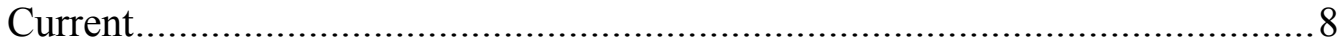

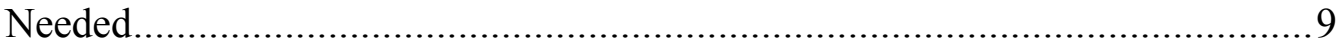 \\ UCG + CCS (Carbon Capture and Sequestration) ......................................... 9 \\ Conventional: process integration ................................................. 10 \\ Unconventional: in-situ process discovery, simulation, and verification ........ 10 \\ Simulation integration, coupling, and field demonstration.............................. 11

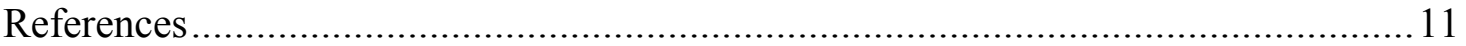

\section{Introduction}

Underground coal gasification (UCG) is an appropriate technology to economically access the energy resources in deep and/or unmineable coal seams and potentially to extract these reserves through production of synthetic gas (syngas) for power generation, production of 
synthetic liquid fuels, natural gas, or chemicals. India is a potentially good area for underground coal gasification. India has an estimated amount of about 467 billion British tons (bt) of possible reserves, nearly $66 \%$ of which is potential candidate for UCG, located at deep to intermediate depths and are low grade. Furthermore, the coal available in India is of poor quality, with very high ash content and low calorific value. Use of coal gasification has the potential to eliminate the environmental hazards associated with ash, with open pit mining and with greenhouse gas emissions if UCG is combined with re-injection of the $\mathrm{CO}_{2}$ fraction of the produced gas. With respect to carbon emissions, India's dependence on coal and its projected rapid rise in electricity demand will make it one of the world's largest $\mathrm{CO}_{2}$ producers in the near future. Underground coal gasification, with separation and reinjection of the $\mathrm{CO}_{2}$ produced by the process, is one strategy that can decouple rising electricity demand from rising greenhouse gas contributions.

UCG is well suited to India's current and emerging energy demands. The syngas produced by UCG can be used to generate electricity through combined cycle. It can also be shifted chemically to produce synthetic natural gas (e.g., Great Plains Gasification Plant in North Dakota). It may also serve as a feedstock for methanol, gasoline, or diesel fuel production and even as a hydrogen supply. Currently, this technology could be deployed in both eastern and western India in highly populated areas, thus reducing overall energy demand. Most importantly, the reduced capital costs and need for better surface facilities provide a platform for rapid acceleration of coal-gas-fired electric power and other high value products.

In summary, UCG has several important economic and environmental benefits relevant to India's energy goals:

$>$ It requires no purchase of surface gasifiers, reducing capital expense substantially.

$>$ It requires no ash management, since ash remains in the subsurface.

$>$ It reduces the cost of pollution management and emits few black-carbon particulates.

$>$ It greatly reduces the cost of $\mathrm{CO}_{2}$ separation for greenhouse gas management, creating the potential for carbon crediting through the Kyoto Clean Development Mechanism.

$>$ It greatly reduces the need to mine and transport coal, since coal is used in-situ.

\section{Major challenges}

Despite the obvious attractiveness of UCG as a cost-efficient process for coal utilization, there are a number of challenges which, when resolved, will accelerate the use of UCG.

\section{Improved process control - volume and quality of gas}

In contrast with surface gasifiers, the boundary and flow conditions in UCG are generally not well known. Likewise, the amount of water influx is also unknown. combined, all these factors make the task of process control more of an art than science. This has a direct bearing on the quantity and quality of the producer gas (or syngas, if oxygen is 
used instead of air). This observation highlights the importance of detailed process and environmental models, as described later in this report.

\section{Understanding of in-situ processes}

A number of processes participate in UCG. The major among them are:

\section{Chemical Reactions}

The overall chemistry underlying the goal gasification processes is well understood. The following table summarizes the important overall reactions participating in the coal gasification process:

Table 1. Fundamental reactions for coal gasification ${ }^{(1)}$

\begin{tabular}{lll}
\hline (1) & $\begin{array}{l}\text { Heterogeneous water gas shift reaction } \\
\mathrm{C}+\mathrm{H}_{2} \mathrm{O}=\mathrm{H}_{2}+\mathrm{CO}\end{array}$ & $\Delta \mathrm{H}=+118.5 \mathrm{~kJ}$ mol-1 \\
(2) & $\begin{array}{l}\text { Shift conversion } \\
\mathrm{CO}+\mathrm{H}_{2} \mathrm{O}=\mathrm{H}_{2}+\mathrm{CO}_{2}\end{array}$ & $\Delta \mathrm{H}=-42.3 \mathrm{~kJ}$ mol-1 \\
(3) & $\begin{array}{l}\text { Methanation } \\
\mathrm{CO}+3 \mathrm{H}_{2}=\mathrm{CH}_{4}+\mathrm{H}_{2} \mathrm{O}\end{array}$ \\
(4) & $\begin{array}{l}\mathrm{Hydrogenating} \text { gasification } \\
\mathrm{C}+2 \mathrm{H}_{2}=\mathrm{CH}_{4}\end{array}$ & $\Delta \mathrm{H}=-206.0 \mathrm{~kJ}$ mol-1 \\
(5) $\quad \begin{array}{l}\text { Partial oxidation } \\
\mathrm{C}+1 / 2 \mathrm{O}_{2}=\mathrm{CO}\end{array}$ & $\Delta \mathrm{H}=-87.5 \mathrm{~kJ}$ mol-1 \\
(6) $\quad \begin{array}{l}\text { Oxidation } \\
\mathrm{C}+\mathrm{O}_{2}=\mathrm{CO}_{2}\end{array}$ \\
(7) $\begin{array}{l}\mathrm{B} \text { oudouard reaction } \\
\mathrm{C}+\mathrm{CO}_{2}=2 \mathrm{CO}\end{array}$ \\
\hline
\end{tabular}

In addition, a number of other reactions also take place, involving the breakdown of the coal matrix by pyrolysis, leading to the formation of lower molecular weight aromatics and other hydrocarbons.

\section{Bulk and in-pore Mass Transfer}

Most reactions listed above are heterogeneous, and occur at the coal/gas interface, or on a catalyst, typically the coal ash. Therefore, the transport of the reactants to the surface, and the products away from the surface, are important. In addition, diffusion of the reactants into the pores in the coal and the ash, and the diffusion of the products out of the pores, are also important. The processes of bulk mass transfer are impacted by the velocity of the reactants across the solid surfaces, whereas the in-pore mass transfer processes are dominated by the pore size and particle size.

\section{Heat Transfer}

Some of the reactions shown in Table 1 are exothermic (2-6), whereas the others (1 and 7) are endothermic. Since it is desirable to minimize (or eliminate) external energy input 
to the gasification process, the endothermic reactions need to be balanced by the exothermic reactions to achieve a stable overall UCG process. The heat transfer in UCG proceeds by all the known heat transfer mechanisms: conduction, convection, and radiation. Conduction creates a thermal wave through the coal matrix ahead of gasification, leading to gaseous combustible products, as well as pollutants. Convection to and from the flowing gas, and radiation to and from the cavity walls, are the mechanism where by heat is transferred across wide distances in UCG.

\section{Fluid flow}

There are a number of major fluid flow processes that determine the progress of the overall UCG process:

- Flow of the reacting gas and products from the injection well to the production well

- Flow of water from the aquifers connected to the coal to the coal surface

- Flow of the pyrolysis products generated during the heating of the coal toward the surface as well as through the cracks and fractures in the coal to the surroundings

\section{Environmental stewardship}

Past tests have shown us that a number of pathways exist by which UCG can lead to negative environmental consequences. The major ones among them are:

- Hot product gases from gasification \& pyrolysis escape into surrounding coal and into connected aquifers

- After the completion of gasification, the gasification cavity is filled with water, and sorbed compounds are leached out

- Gasification cavity collapse may have connected the coal aquifer to a previously unconnected aquifer

A number of processes influence the fate and transport of the contaminants generated by the UCG process:

- Thermally-driven upward flow of groundwater resulting from in situ burning of coal;

- Buoyancy effects from fluid density differences reflecting gradients in dissolved solids content and temperature of groundwater;

- Differential pressure during and after operations between the burn cavity and the ambient hydrologic pressure in the surrounding rock. Partitioning of organic compounds and dissolved metals onto mineral surfaces during solute transport;

- Bioattenuation of organic compounds derived from coals that migrate into potable water aquifers.

\section{Carbon management}

A number of strategies can be used for carbon management: 


\section{Location of Carbon (CO2) Capture}

The $\mathrm{CO} 2$ can be captured at various locations in the UCG and power production process:

- It can be separated from the syngas (or producer gas) above ground, using any one of the processes described below ${ }^{(2)}$

- It can be separated from the syngas using a downhole separation process (LLNL proprietary)

- The $\mathrm{CO}_{2}$ can be separated from the flue gas using using any one of the processes described below ${ }^{(2)}$

- If pure oxygen is used for gasification and combustion (combined with $\mathrm{CO}_{2}$ recycle for temperature control), the products of combustion will be steam and $\mathrm{CO}_{2}$, which can be separated by condensing out the steam.

\section{Separation Technologies}

A number of technologies for separation of $\mathrm{CO} 2$ from other gases (mainly hydrogen and nitrogen in the current context) exist commercially ${ }^{(2)}$ :

- Pressure Swing Adsorption

- Separation using solvents, such as amines or water

- Membrane separation

- Cryogenic separation

- Advanced technologies under development include electrochemical separation

\section{Storage}

Among the potential candidates for the storage of $\mathrm{CO} 2$ are:

- Saline aquifers

- Depleted oil and gas fields, with or without enhanced oil recovery of enhanced gas recovery)

- Unminable coal seams, with or without enhanced coal bed methane recovery

- Cavities created by UCG

\section{Engineering integration \& economics}

One of the major challenges in UCG is the creation of a viable link between the injection well and the production well. Over twenty years ago, LLNL developed a method known as CRIP (Continuous Retraction Injection Point) for efficient production of synthetic gas from underground coal seams. As shown in Figure 1, this method of production uses vertical production gas wells and a directionally drilled, horizontal well through the lower part of the coal seam. 


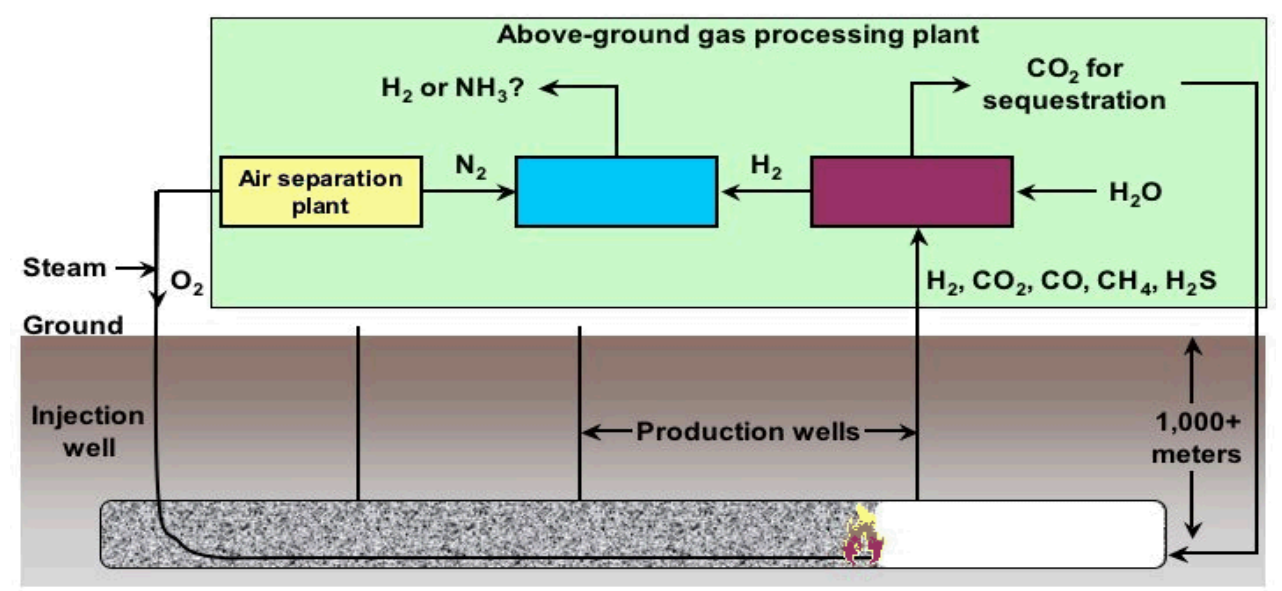

Figure 1: A schematic of the CRIP process

The CRIP process retracts the combined steam and oxygen injection point to control the location of the combustion front.

Ergo-Exergy of Canada has developed a different technique to produce the linkage. The new proprietary process is termed e- $\mathrm{UCG}^{(3)}$.

\section{Major technical gaps}

\section{Improved combustion/gasification models}

\section{Current}

\section{Combustion simulation}

In general, the basics of combustion processes are well understood. A number of national laboratories and universities have the general capability to address issues of ignition, flame extinction, emissions, performance modification both for enhancement and for inhibition of combustion, and overall performance for a wide range of practical fuels, and have the capability to develop comparable models for fuels not previously studied.

\section{UCG Process Models}

Extensive modeling of UCG processes was done at the Lawrence Livermore National Laboratory during the late $70 \mathrm{~s}$ and mid $80 \mathrm{~s}^{(4-19)}$, using the best tools available at that time. However, major changes have taken place in computers, software and the methodology of modeling in the last twenty years. In addition, more has been learned on the mechanism of how pollutants leave the gasification zone and move to the surroundings. For these reasons, the currently available models are insufficient to address the current problems encountered in UCG. In addition, a number of environmental fate and transport models have been developed, which are disjoint with the existing process models.

\section{Needed}

\section{Improved UCG models using CFD}

LLNL and others have already started develop improved UCG models using computational fluid dynamics $(\mathrm{CFD})^{(20,21)}$. While these models constitute a step in the 
right direction, a number of improvements are needed before these models can be used for design, operation and control of UCG processes:

- Steady-state $\rightarrow$ Dynamic: The current CFD models are steady state, whereas in actuality, UCG processes are transient.

- $\quad$ 2-D $\rightarrow$ 3-D model; no axial symmetry: The current models are 2-D axisymmetric, whereas in reality, a UCG process geometry is 3 dimensional and asymmetric

- Increase the length of the channel: Due to memory limitations, the LLNL model is limited to short lengths compared to actual UCG in the field.

- Include radiation: The LLNL model ignores radiative heat transfer, which, as high flame and wall temperatures can be significant

- Calculate local recession rate for coal: both models ignore local recession rates of coal, whereas the coal recession rate is the main determinant of the cavity growth rate

- Incorporate full product prediction: Combustion simulations should predict the formation, disposition, and production of complex gasification and partial combustion species. This includes produced tars, the down-hole char, and the fate of sulfur, mercury, and particulates.

\section{Integration into Aspen models}

The CFD models of UCG, mentioned above, are stand-alone models, and are not coupled with above-ground facilities. It would be very useful to couple the UCG process models with the above-ground facilities models, developed using a process simulator, such as AspenPlus, so that the entire process can be modeled at once, rather than sequentially.

\section{Improved monitoring}

\section{Historical}

To date, monitoring of UCG experiments and commercial operations has been quite limited. Usually, it involved placement of thermocouples in monitoring wells above shallow burns (REF). Limited attempts have been made to test EM induction tools. In the Chinchilla experiment, groundwater pressure and composition was monitored in 19 wells surrounding the burn (REF). As such, no UCG project has been monitoredin such a fashion as to give detailed process control information or to show the evolution of the insitu reactor.

\section{Tools}

While there are numerous possible tools for UCG monitoring, a small set of geophysical tools show particular promise in resolving process information and providing real-time information to operators. These are all essentially off-the-shelf technologies that could be immediately deployed in UCG monitoring, although the could be tailored to the task.

- Electrical resistance tomography (ERT) and EM induction tomography (EMIT) 
- Passive seismic monitoring (e.g., microseismic)

- Crust deformation tools, such as tilt-meter, InSAR and GPS

- Down-hole temperature, pressure, and chemical monitoring

Although 3D and 4D reflection seismic monitoring could also provide key information, the high cost and long processing times limit its potential utility.

\section{Likely learnings from field deployment}

A number of key learnings would come from direct subsurface monitoring during UCG. The first of these would be to provide real-time insight into potential hazards from UCG (e.g., subsidence, contaminant transport). The second would be to validate and improve simulations of UCG processes. The third is to improve understanding of key processes in the subsurface (e.g., geomechanical response to heating and evacuation of coal). Finally, monitoring holds out the possibility of real-time process control through rapid integration of monitoring data.

In addition to these scientific and technical values, there would be tremendous value for the commercial sector and key stakeholders (e.g., regulators, insurers, public agents) in the demonstration of knowledge, control, and predictability of in-situ coal conversion.

\section{Improved environmental simulation}

\section{Current}

Even though most UCG operations have not produced any significant environmental consequences, some UCG demonstrations (including two in the U.S.) resulted in contamination of groundwater resource. Integrated site-selection, operational and monitoring guidelines need to be developed to assure that all future UCG operations pose minimal risk to the environment.

The standard types of hydrologic models used for environmental assessments are not appropriate for UCG and if used, may give spurious results. These models do not include consideration of the full suite of effects of UCG operations, all of which can greatly influence flow fields and the consequent fate and transport of contaminants during or after the burn. Specifically, models must include thermo-hydro-geochemicalgeomechanical coupled processes to fully understand the risk to the subsurface environment of UCG, and how to reduce the risk of contamination from $\mathrm{CO}_{2}$ leakage and/or seam collapse in the case of coupled UCG-CSS.

There are existing simulation tools available that can be linked and adapted to environmental risk assessment for UCG. Some of these were developed to provide environmental assessments for underground nuclear tests or to model nuclear storage scenarios that require consideration of the impact of thermal and geomechanical changes to flow fields. Examples include FEFLOW (a commercially available finite element simulator for modeling of flow and transport processes in porous media under saturated and unsaturated conditions that includes provision for density driven flow from thermal 
effects) and NUFT (a finite-difference based reactive transport model developed at LLNL). With respect to capturing geomechanical aspects, LLNL has a toolbox of forward and inverse geophysical solvers to model acoustic, thermal, electrical, deformational and gravitational transients, and integration and inversion techniques, including stochastic inversion using Monte-Carlo Markov-chain approaches. These tools are appropriate both for environmental risk assessment modeling and for interpretation of geophysical monitoring data.

\section{Needed}

While there is much work still to be done to create and integrated simulation model for UCG environmental risk assessment from existing component models, there is a larger gap to be filled with regard to the data needed to populate and test the model. These data gaps include:

1. Identification of parameters controlling fate and transport (e.g., water solubility, organic carbon partitioning coefficient) for the potential contaminant compounds that may be generated by in situ burning of coal .

2. Quantification of changes in the hydraulic conductivity tensor and porosity reflecting rock crushing and possible of fracture/fissure propagation in the vicinity of the collapsed zone.

3. Model calibration to post-seam collapse hydraulic head and concentration measurements for pilot sites where historical data are available

4. Assembly of the thermo-hydrological model and calibration to existing thermohydrological data such as temperature profiles.

5. Coupling the thermal effects on the density and viscosity to better mimic the pertinent physical processes and quantitative assessment of the effects of the thermally- and density- driven forces on the risk of contaminant migration.

6. Quantification of bioattenuation effects (with bioattenuation rates derived from a literature review) and comparison to existing data, including the abundant literature describing hydrocarbon contamination migration in shallow groundwater systems.

Also, research is needed to ensure that the models can be used to screen candidate sites to provide criteria for proper site selection, addressing both the desired conditions for suitable UCG processes and conditions that minimize risk of contaminating groundwater resources. What is needed is a unified and integrated model that incorporates all the component models mentioned here: CFD process model for UCG; above-ground facilities model in Aspen; and the pollutants generation, fate and transport model.

\section{UCG + CCS (Carbon Capture and Sequestration)}

There exists a strong synergy between UCG and carbon sequestration. In some cases, there may be substantial cost reductions in carbon capture and separation due to the high temperatures and pressures available from UCG syngas streams. As mentioned earlier, the cavity developed during the course of UCG might be used for storing supercritical carbon dioxide. In all cases, it is highly likely that the neighboring rocks will contain 
saline formations (non-potable aquifers) or depleted oil and gas fields suitable for storing $\mathrm{CO}_{2}$.

\section{Conventional: process integration}

In the most likely case wherein neighboring formations are used for storage, the site characterization and storage risks are likely to be similar to conventional CCS sites (Blinderman and Friedmann, 2006). However, important gaps remain regarding how UCG operations might be reasonably integrated into commercial operations. Engineering considerations, potential systems feedbacks, and likely costs need to be considered as part of a system characterization. While it is not expected that this step is likely to be difficult technically, the gap remains today and requires some focus and study.

\section{Unconventional: in-situ process discovery, simulation, and verification}

Should one try to store $\mathrm{CO} 2$ in the evacuated reactor zone, much less is known about ht likely risks of storage. This initial list delineates some of the larger concerns and attempts to bound the necessary science to begin to address them.

- T-P constraints: The cavity temperature at a given pressure must be sufficiently low to avoid flashing or boiling of $\mathrm{CO}_{2}$ at injection pressures. Similarly, the injection pressure must be sufficient to remain supercritical and ideally to prevent flashing. The risk of sudden phase change must be well understood as an initial condition for cavity injection, and will require both experiments and simulation.

- Geomechanical response: The injection pressure must exceed hydrostatic pressures in order to displace cavity water. This will prompt a number of geomechanical responses, such as fracture dilation, crustal uplift, and potentially inducing fracture. These will vary as a function of stress tensor and fracture geometry, which may be difficult to characterize in this setting. This risk may be accentuated by the collapse of the cavity roof or walls. In contrast, coal swelling will cause fracture closure. Valid geomechanical models for stress and rock deformation are required, as are coupled geomechanical/fluid-flow simulators.

- Ground-water displacement risk: Cavity injection above hydrostatic pressures will displace cavity brines into the coal seam and adjoining formation. This may flush VOCs or high metal concentrations from the cavity into saline aquifers or coals. The nature of these materials should be circumscribed, and the concentrations and fate of these materials reasonably well characterized through experiments and simulations

- Geochemical response: $\mathrm{CO}_{2}$ injection will form carbonic acid in the cavity, which may react quickly with the coal, rock, ash, or slag in the cavity. This could leach metals into the cavity water elevating risk of groundwater contamination. Similarly, injection could mobilize sulfur from these materials to form sulfuric acid, further altering the local chemistry and increasing risk. VOCs could dissolve into the $\mathrm{CO}_{2}$ and move with mobile phases. The key suite of reactive species for typical coals should be studied experimentally as a basis for reactive transport simulation. 
- $\mathbf{C O}_{2}$ fate: Free-phase $\mathrm{CO}_{2}$ would remain supercritical and buoyant. This would create its own upward pressure on the cavity, and lead to the same set of risks commonly considered for conventional $\mathrm{CO}_{2}$ storage. In this environment, the geomechanical, fault migration, and well-leakage risks may be greater due to the thermal stresses and shocks of heating and quenching. The specific leakage risks for cavity storage should be further delineated and considered in concert with conventional processes (e.g., coal-gas adsorption).

The magnitude of these scientific tasks is great, and the system both non-linear and poorly constrained. As such, a substantial research effort would be required to being addressing chief concerns. However, the advantages could still be substantial, and if sites are chosen properly to reduce stratigraphic and structural risks, the concerns may be reasonably managed.

\section{Simulation integration, coupling, and field demonstration}

Site and process considerations are inter-dependent, one will affect the other. The parameters associated with the relevant process need to be explored to identify, in a quantitative context, which scenarios are most favorable and which are least, for UCG at a particular site. Also, the coal seam should be located in a region where the products of UCG can be used; otherwise an expensive transportation or conversion scenario would develop. Once the models are unified, such considerations will be an integral part of the model, rather than ad hoc, stand-alone factors to be considered in series.

A thoughtful, targeted research program could serve to better delineate the key aspects of UCG risk. Such a program would necessarily have a large component of simulation and laboratory work, given the lack of storage efforts at any current UCG field sites (many of which are too shallow for $\mathrm{CO}_{2}$ injection). Improved geomechanical models would be central to this effort, and should be able to simulate both discrete fracture networks and tunnel collapse due to stress changes. Good simulations would also have some stratigraphic richness regarding the hosting and suprajacent strata and should be supported by focused laboratory experiments conducted on materials of chief concern (e.g., tars, chars, and slagged ash). Each of the topical areas would require some focus, and a substantial risk assessment should be undertaken before a field site is selected for $\mathrm{CO}_{2}$ cavity injection

\section{References}

1. Hottel, H.C., and J.B.Howard, "New Energy Technology", The MIT Press, Cambridge, Massachusetts, 1971

2. Halmann, Martin M and Meyer Steinberg, "Greenhouse Gas Carbon Dioxide Mitigation”, Lewis Publishers, 1999.

3. http://www.ergoexergy.com/eucg.htm 
4. Thorsness, C B , "Lawrence Livermore National Laboratory underground coal gasification project: final report", UCID-21853, 1989

5. Britten, Jerald A, "Further Development Of An Axisymmetric Global Ugg Cavity Growth Simulator", UCRL-96461-abstract, 1987

6. Thorsness, Charles B, "Unconfined Flow As A Mechanism Of Water Influx To A UCG System”, UCRL-97203, 1987

7. Kang, Sang-wook, "Numerical Analysis Of Packed-bed Flow Processes”, UCRL93984-abstract, 1986

8. Thorsness, Charles B, "General-purpose, Packed-bed Model For Analysis Of Underground Coal Gasification Processes", UCID-20731, 1986

9. Kang, S W, "Transient, Multicomponent Flows Through Packed Beds", UCRL-93748, 1986

10. Britten, J A, " Mechanistic Model For Axisymmetric Ucg Cavity Growth. Part 2, Parameter Study And Comparison With Field Data", UCRL-94420-abstract, 1986

11. Kang, S W, "Computational Packed-bed Analysis Related To Coal Gasification Processes", UCRL-94421-abstract, 1986

12. Thorsness, C B, "Mechanistic Model For Axisymmetric Ucg Cavity Growth. Part 1, An Overview",UCRL-94419-abstract, 1986

13. Kang, Sang-wook, "Transient, Multicomponent Flows Through Packed Beds", UCRL-93748-revision-1, 1986

14. Thorsness, Charles B, "Mechanistic Model For Axisymmetric Ucg Cavity Growth", UCRL-94419, 1986

15. Grens, E A, "Effect Of Non-uniform Bed Properties On Cavity Wall Recession", UCRL-92487-abstract, 1985

16. Britten, Jerald A, "Modeling Thermal And Material Interactions Between A

Gasifying Char Bed And A Drying/spalling Coal Roof", UCRL-92488-abstract, 1985

17. Thorsness, C B, "Further Development Of A General-purpose, Packed-bed Model For Analysis Of Underground Coal Gasification Processes”, UCRL-92489-abstract, 1985

18. Britten, Jerald A, "Modeling Thermal And Material Interactions Between A Reacting Char Bed And A Gasifying/spalling Coal Roof", UCRL-92488, 1985 
19. Grens, Edward A, "Effect Of Non-uniform Bed Properties On Cavity Wall Recession", UCRL-92487, 1985

20. Wallman, Henrik, "Model for Underground Production of H2 from Coal", internal report, 2005

21. Perkins, Greg, "Numerical modelling of underground coal gasification and its application to Australian coal seam conditions", 2005

http://www.ac3.edu.au/edu/papers/perkinsg01.pdf 